\title{
Effect of combining anti-epidermal growth factor receptor antibody C225 and radiation on DU145 prostate cancer
}

\author{
MATTHEW WAGENER ${ }^{2}$, XIAOCHUN ZHANG ${ }^{2}$, \\ HUMBERTO G. VILLARREAL ${ }^{2}$, LARRY LEVY ${ }^{1}$, PAMELA ALLEN ${ }^{1}$, \\ SHUJUN SHENTU ${ }^{2}$, BINGLIANG FANG ${ }^{3}$, SUNIL KRISHNAN ${ }^{1}$, \\ JOE Y. CHANG ${ }^{1}$ and M. REX CHEUNG ${ }^{1}$
}

\begin{abstract}
Departments of ${ }^{1}$ Radiation Oncology, ${ }^{2}$ Experimental Radiation Oncology and ${ }^{3}$ Thoracic and Cardiovascular Surgery, UT MD Anderson Cancer Center, 1515 Holcombe Boulevard, Houston, TX 77030, USA
\end{abstract}

Received September 27, 2007; Accepted November 1, 2007

\begin{abstract}
The epidermal growth factor receptor (EGFR) network has rich targets for prostate cancer killing. Herein we evaluated the effects of combining the EGFR inhibition and radiation on DU145 prostate cancer. We treated DU145 prostate cancer cells with various doses of anti-EGFR antibody (C225) and $\gamma$-irradiation (RAD). The effects of the treatment on cell viability and growth were assessed with cell counting, $\mathrm{XTT}$ and clonogenic assays. In vivo treatment effects were assessed using a subcutaneous tumor xenograft in mice. Cell cycle distribution and progression were assessed with flow cytometry. The apoptotic components of cell death were quantified using Annexin-V binding assays. The results demonstrated that when combined with radiation, C225 augmented the inhibition of cell viability and growth in the DU145 cell line and EGFR inhibition appeared to have some interaction with RAD. C225 inhibited the growth of implanted DU145 tumors and increased the efficacy of radiation treatment. Flow cytometric analysis suggested that mostly necrotic cell death resulted from the EGFR inhibition or irradiation, although there may be some apoptosis. We drew the conclusion that the inhibition of EGFR augments the radiation killing of DU145 prostate cancer via a combination of cytostatic, necrotic and apoptotic mechanisms.
\end{abstract}

\section{Introduction}

Prostate cancer is a common malignancy that is expected to afflict $\sim 230,000$ new patients in 2004 with an estimated

Correspondence to: Dr M. Rex Cheung, Department of Radiation Oncology, UT MD Anderson Cancer Center, 1515 Holcombe Boulevard, Houston, TX 77030, USA

E-mail: mrcheung@mdanderson.org

Key words: DU145, prostate cancer, epidermal growth factor receptor, anti-epidermal growth factor receptor antibody, radiation sensitivity mortality of 29,900 deaths (1). In the era of PSA screening, most of the prostate cancer patients are diagnosed at a localized stage (2). Radiotherapy is an accepted treatment modality for prostate cancer (3) while advances in anatomical imaging have allowed for a better target definition and dose escalation to improve treatment outcome $(4,5)$. However, there is concern that further dose increase may lead to more toxicity. In a combined treatment, a long-term androgen deprivation of 2-3 years has been shown to improve the outcome without a dose escalation beyond the conventional 70 Gy (6). However, long-term hormone treatment has been shown to have significant side effects (7). A short-term 6-month androgen suppression has recently been advocated (8), but its side effects may also be substantial (9). An alternative to radiation dose escalation or hormone supplementation would be to use molecularly-targeted prostate cancer killing. The epidermal growth factor receptor (EGFR) pathway is emerging as a promising target for prostate cancer killing and potential radiation sensitization $(10,11)$. However, the interactions between EGFR and radiation sensitivity in prostate cancer cells are not well characterized. The main goal here was to investigate the potential of using the $\mathrm{C} 225$ inhibition of EGFR to augment the radiation killing of prostate cancer. We were also interested in finding out if a synergistic interaction existed between EGFR inhibition and radiation.

\section{Materials and methods}

Cell culture and reagents. The prostate cell lines DU145 were obtained from the American Type Culture Collection (ATCC, Manassas, VA). The cells were maintained in a humidified incubator at $37^{\circ} \mathrm{C}$ with $5 \% \mathrm{CO}_{2}$ in Roswell Park Memorial Institute (RPMI)-1640 medium supplemented with $10 \%$ heatinactivated fetal bovine serum, $1 \%$ glutamine and $1 \%$ antibiotics. The monoclonal antibody C225 (MW $152 \mathrm{kDa}$ ) was purchased from ImClone Systems, Inc. Recombinant human EGF (MW 6.215) was purchased from Sigma Chemical Co. (St. Louis, MO).

In vitro treatments and proliferation assays. The inhibition of tumor cell growth by combination treatments with EGFR 
inhibition and radiation were analyzed quantitatively by cell counting and XTT (Roche Molecular Biochemicals, Indianapolis, IN) assays. Cell counts were measured from samples prepared for flow cytometry studies as described below. For XTT viability assays, an appropriate number of cells was plated in 96-well micro-liter plates (BD Falcon) plated in $100 \mu \mathrm{l}$ medium and incubated overnight. The media were removed and replaced with $100 \mu 1$ media containing different concentrations of EGF and C225 up to $100 \mathrm{nM}$ for a few hours. The cells were irradiated with various doses of $\gamma$-radiation in an external ${ }^{137} \mathrm{Cs}$ source unit at room temperature. The treated cells were incubated for 2-4 days. The media were replaced with fresh media $(100 \mu 1)$. XTT reagents were mixed and $50 \mu 1$ of XTT was added to each well. Cells were then incubated at $37^{\circ} \mathrm{C}$ in a humidified atmosphere with $5 \%$ $\mathrm{CO}_{2}$. From our exploratory studies, we found that incubating 2000 DU145 cells for $2 \mathrm{~h}$ gave a reasonable signal to the noise ratio. The optical absorption was measured by a plate reader (Perkin Elmer, Wallac Victor3 1420 multi-label counter) at $490 \mathrm{~nm}$ around the absorption peak of XTT (12). The XTT measure-ments were normalized to those of the untreated cells of each experiment. Experiments were repeated at least twice.

Clonogenic survival assay. Cells were cultured in $10-\mathrm{cm}$ dishes or T25 flasks in normal culture medium overnight. Cells were then treated with up to $20 \mathrm{nM} \mathrm{C} 225$ or EGF for at least a few hours and up to $24 \mathrm{~h}$. Cells treated with phosphate-buffered saline (PBS, obtained from ATCC) alone, or no treatment, were used as a control. The cells were irradiated with various doses of radiation in a ${ }^{137} \mathrm{Cs}$ unit at room temperature and removed by trypsin and counted (Beckman Coulter Cell and Particle Counter). Cells (100-1000) were plated depending on the strength of the treatment conditions in $10 \mathrm{ml}$ of media in triplicate. The cells were incubated in a $37^{\circ} \mathrm{C}, 5 \% \mathrm{CO}_{2}$ incubator without disturbance for 12-14 days, and then fixed and stained with ethanol with $10 \%$ crystal violet. Colonies with $>50$ cells/colony for DU145 cells were counted.

Cell cycle analysis by flow cytometry. Cells (1-2 million) were plated in $10-\mathrm{cm}$ dishes and were incubated overnight and then treated with $\mathrm{C} 225$ or EGF at various concentrations. Cells treated with PBS alone, or no treatment, were used as a control. After a few hours to 1 day of exposure to $\mathrm{C} 225$ or $\mathrm{EGF}$, the cells in the $10-\mathrm{cm}$ dishes were irradiated with various doses of radiation at room temperature. The cells were incubated for 2-4 days, removed by trypsinization and counted, fixed with either 70 or $100 \%$ ethanol and stored at $4^{\circ} \mathrm{C}$, and then stained with Propidium iodide (PI, Sigma). The distribution of DNA content was measured by flow cytometry at UTMDACC Flow Cytometry Core Laboratories.

Assessment of the treatment using subcutaneous implanted tumors in mice. This study was approved by the UT MDACC Institutional Animal Care and Use Committee. Human DU145 tumor cells $\left(2 \times 10^{6}\right)$ were injected subcutaneously into the right hind thighs of 6-8 week old, male Swiss mice. Treatment of the xenograft tumors started at $\sim 5 \mathrm{~mm}$ diameter. C225 (1 mg/mouse) was injected intraperitoneally. Radiation, using a Cesium-137 source, was given $6 \mathrm{~h}$ after the drug treatments (13). Mice were immobilized with surgical tape and localized radiation was delivered to the leg that bore the tumor only. The rest of the body was shielded with lead block. Nembutal was used for anesthesia. The short (r) and long (R) axes of the tumors were measured three times a week. The tumor volumes were estimated using the ellipsoid formula [volume $\left.=\left(\pi R^{*} r^{*} \mathrm{r}\right) / 6\right](14)$.

Assessment of the degree of apoptosis. Cells were plated in $10-\mathrm{cm}$ dishes at 1 million cells and incubated overnight. The media was removed and replaced with media $(10 \mathrm{ml})$ containing different concentrations of C225 or EGF. After a few hours of treatment, the dishes were irradiated with various doses of radiation in a ${ }^{137} \mathrm{Cs}$ unit at room temperature. The cells were incubated for 2-4 days. The treated cells were trypsinized, removed and counted (Coulter Counter) according to the manufacturer's instructions. The cells were dually stained by Annexin V:FITC (15) (Annexin V:FITC Apoptosis Detection Kit I, BD Pharmigen) and PI according to the manufacturer's instructions. Flow cytometry was performed at the UTMDACC flow cytometry core. The total Annexin-V binding was used as a measure of the degree of apoptosis in this study. Cells were also counted to assess treatment effects. The cell counts were normalized to those of the untreated controls.

Statistical analysis. Statistical routines from SAS 9.1 (Cary, NC) and SPSS 11.5 (Chicago, IL) were used for analysis. The relationship between the cellular outcome and treatments were estimated with regression models as implemented in PROC GLM and MIXED in SAS. The data cell viability tests were first normalized to the observed values of the controls for the particular experimental date. The surviving fraction (SF) was then modeled using the standard parameterization: $\mathrm{SF}=\exp \left(-\mathrm{b}_{1}{ }^{*} \mathrm{RAD}-\mathrm{b}_{2} * \mathrm{C} 225-\mathrm{b}_{3}{ }^{*} \mathrm{EGF}-\mathrm{b}_{4}{ }^{*} \mathrm{RAD} * \mathrm{C} 225\right.$ $\left.-\mathrm{b}_{5} * \mathrm{RAD} * \mathrm{EGF}\right)$, where exp was the exponential function, RAD was the radiation dose in Gy, C225 was the nanomolar concentration of $\mathrm{C} 255$, EGF was the nanomolar concentration of EGF and $b_{1}, b_{2}, b_{3}, b_{4}$ and $b_{5}$ were the estimated regression coefficients. We sought to quantify the effect of C225 on the radiation-induced DU145 growth delay of the xenograft tumor. To this end, the analysis of mice tumor growth was generated using PROC MIXED in SAS (16). Annexin-V binding data were fitted with a regression equation in linear form with the date of the experiment modeled as a random effect. Statistical significance for the main effects and interactions was set at $\mathrm{p}<0.05$ for all analyses. The data for the cell cycle were modeled using the generalized linear model in SPSS.

\section{Results}

Fig. 1 shows the effects and interaction between C225, EGF and RAD on DU145 cell viability and growth. The signal to noise ratio when 200 DU145 cells were incubated in XTT for $2 \mathrm{~h}$ was $\sim 5: 1$. We considered this a reasonable signal to noise separation to perform our experiments. Fig. 1a shows a dosedependent inhibition of DU145 cell viability with C225. For $\mathrm{C} 225$ and RAD, the p-value for the main effect was 0.001 for C225, 0.001 for RAD and 0.102 for the C225-by-RAD 


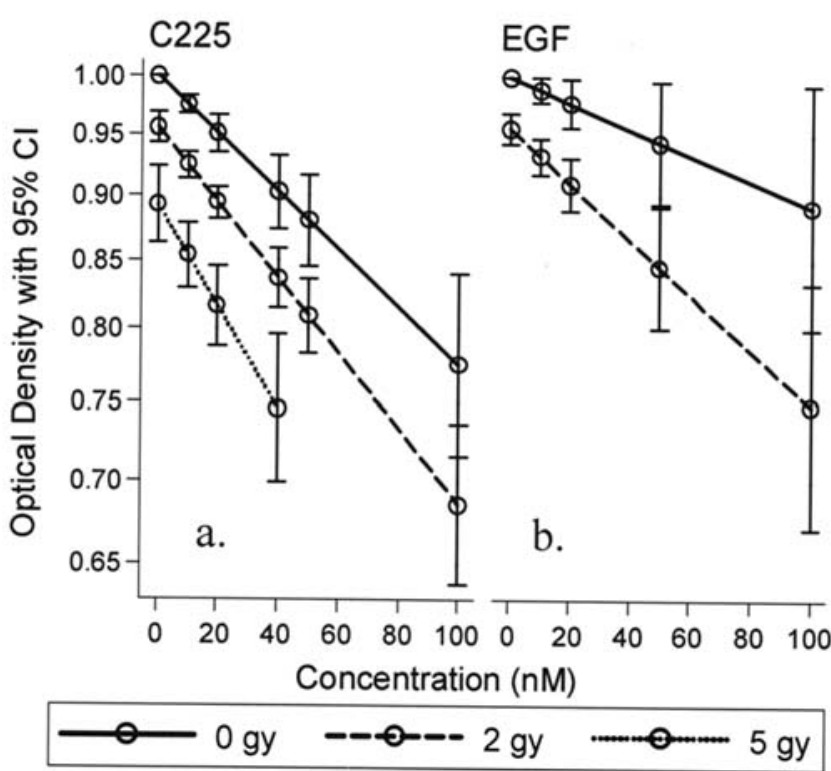

Figure 1. The effect of a) C225 and b) EGF with or without RAD on cellular viability and growth using XTT assays for DU145 cells. The error bars represent the $95 \%$ confidence intervals.

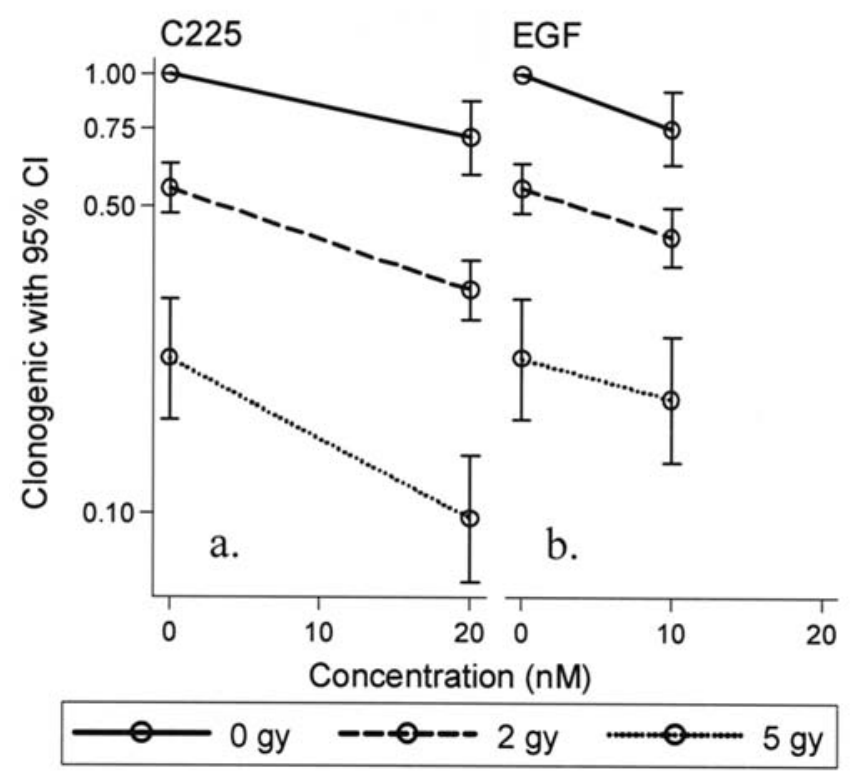

Figure 2. The effect of a) C225 and b) EGF with or without RAD on the clonogenic potential of DU145 cells. The error bars represent the $95 \%$ confidence intervals.

interaction. Fig. 1b shows an inhibitory effect of EGF on the DU145 cells with or without 2 Gy irradiation. The p-value for the main effect was 0.035 for EGF, 0.001 for RAD and 0.098 for the interaction term EGF-by-RAD.

Fig. 2 shows the effects of EGF, C225 and RAD on the clonogenic assays of DU145. For C225 and RAD, the p-value for the main effect was 0.001 for C225, 0.001 for RAD and 0.061 for the interaction C225-by-RAD (Fig. 2a). For the DU145 cells, the p-value for the main effect was 0.005 for EGF, 0.001 for RAD and 0.784 for the EGF-by-RAD interaction (Fig. 2b).

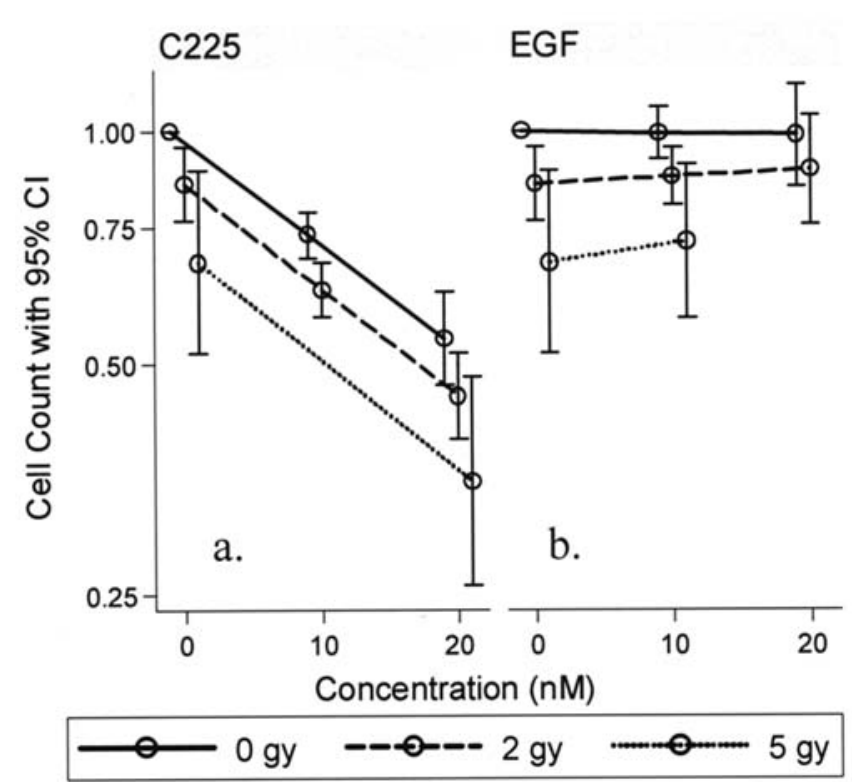

Figure 3. The effect of a) C225 and b) EGF with or without RAD on the proliferation potential of DU145 cells as quantified by cell counting. The error bars represent the $95 \%$ confidence intervals.

EGFR inhibition decreased DU145 cell proliferation as assessed by cell counting (Fig. 3). Fig 3a shows that C225, but not EGF, decreased the cell counts of the Du145 cells in a dose-dependent manner with or without radiation (Fig. 3a). The p-value for the main effect was 0.006 for RAD, 0.001 for C225 and 0.867 for the C225-by-RAD interaction (Fig. 3a).

Fig. 4 shows data of the growth of the tumor volume for 25 mice. An average of 14 measurements of the tumor volume were taken per mouse for up to 32 days post-treatment. The treatment consisted of three combinations of radiation dose in 0,2 , or $5 \mathrm{~Gy}$, with or without $1 \mathrm{mg}$ of C225. These level-two variables in the hierarchical model (radiation dose, C225) were modeled as continuous and indicator variables respectively, with the level-one variable (day) modeled as a continuous variable. A statistically significant daily growth rate of -0.029 was estimated for the administration of $1 \mathrm{mg}$ of C225 ( $<<0.0001)$ by the likelihood ratio Chi-square test. The estimate effect on the growth rate of an additional $1 \mathrm{~Gy}$ was estimated to be $-0.003(\mathrm{p}=0.056)$, also by the likelihood ratio Chi-square test.

Fig. 5 shows the effects of C225 on the cell cycle distribution of DU145 cells. C225 increased the percentage of DU145 cells in G1 and decreased the percentage of cells in the $\mathrm{S}$ phase without (Fig. 5a) or with irradiation (Fig. 5b). However, these differences were not statistically significant. The regression lines were fitted to the mean values to illustrate the trends (Fig. 5). EGF did not have consistent effects on the cell cycle progression of DU145 cells. EGFR inhibition also led to a small increase in the sub-G fraction of DU145 cells (Fig. 5).

Fig. 6 shows the effects of C225, EGF and RAD on the levels of the Annexin-V:FITC binding of DU145 cells. C225 increased the Annexin-V binding and labeling further increased when these cells were irradiated with $2 \mathrm{~Gy}$, suggesting an enhancement in apoptosis. 


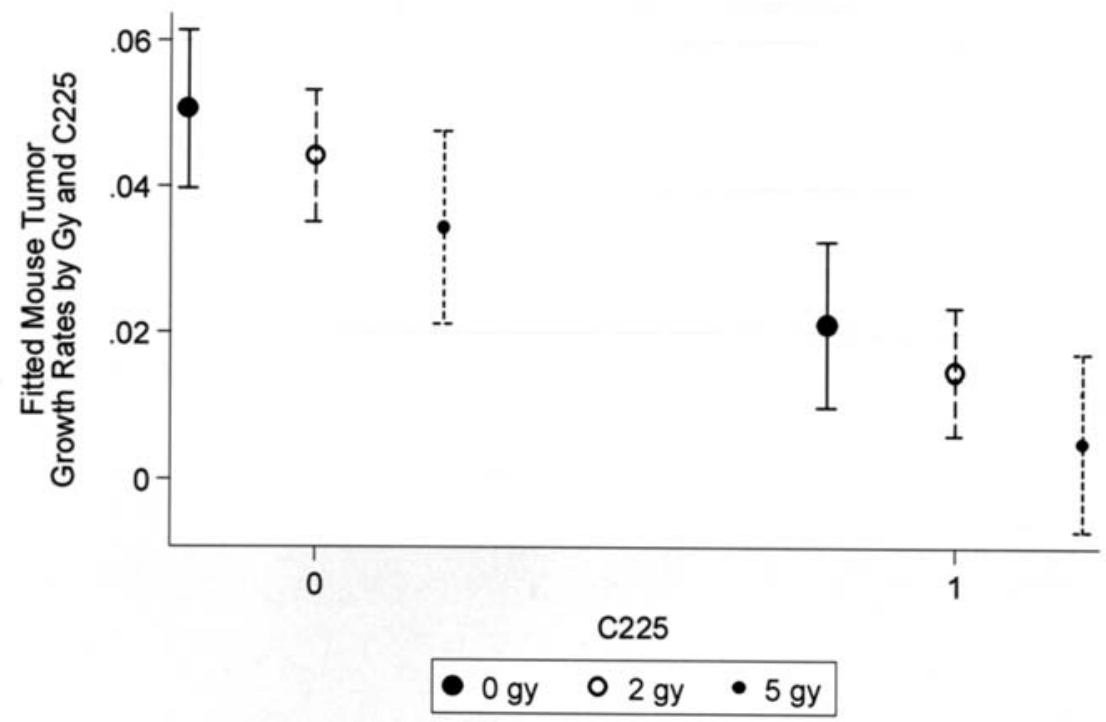

Figure 4. The anti-tumor effect of $1 \mathrm{mg} /$ mouse C225 with or without RAD on the growth rate of DU145 tumor cells implanted subcutaneously in the hind thighs of Swiss mice. The error bars represent the $95 \%$ confidence intervals.
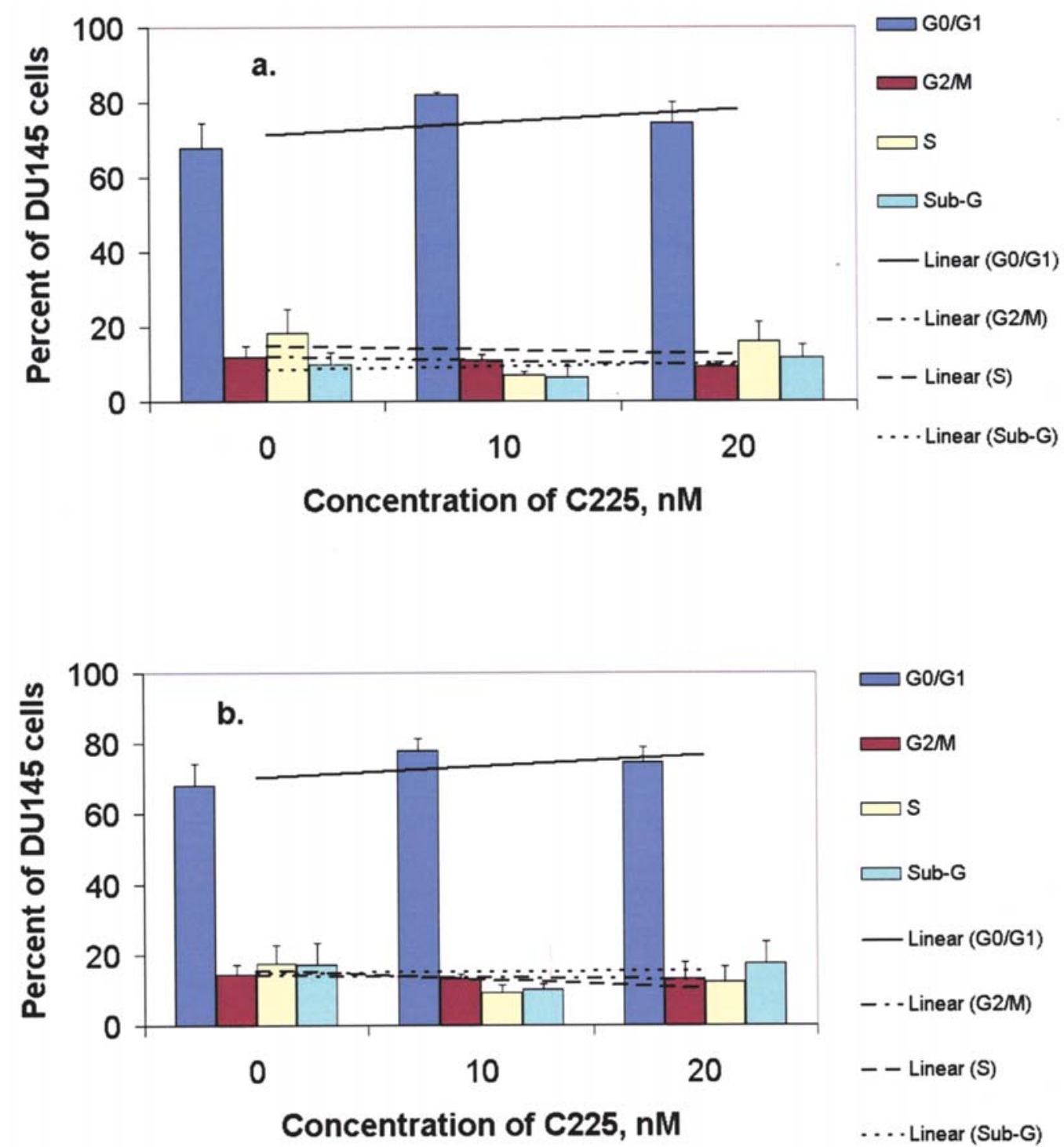

G0/G1

G2M

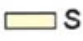

$\varpi$ Sub-G

- Linear (G0/G1)

- - - Linear (G2M)

-- Linear $(S)$

$\cdots$ Linear (Sub-G)

Figure 5. The effect of C225 on the cell cycle distribution of DU145 cells a) without radiation and b) with 2 Gy irradiation. The sub-G percentages were those of the total number of cells. The percentages of cells in the G1, G2 and S phases were those of the live cells. 


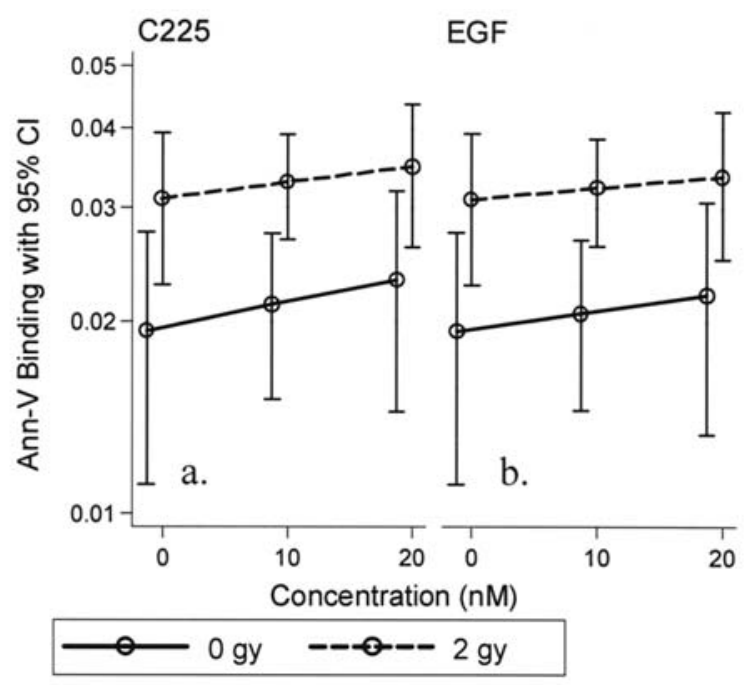

Figure 6. The effect of C225 on Annexin-V:FITC labeling with and without irradiation.

\section{Discussion}

EGFR is a 1186 amino acid transmembrane glycoprotein with a 23 amino acid transmembrane domain separating the extracellular EGF binding domain and the intracellular tyrosine kinase domain (17). The physiology of EGF binding to EGFR expressing cells has been extensively studied (18). The binding of the 53 amino acid EGF to the extracellular domain of EGFR has been resolved to $3.3 \AA$ (19). The EGF binding to EGFR leads to the dimerization of EGFR and phosphorylation of its carboxyl activation loop (20). This causes a conformation change of EGFR that activates its tyrosine kinase domain. A stimulated EFGR activates a network of downstream signal transduction kinases. This network includes the Ras/Mitogen-Activated Protein Kinase (MAPK), phosphatidylinositol-3-kinase/protein kinase B (Akt) and phospholipase-C/protein kinase C pathways (20). EGFR activation promotes cell cycle progression and cellular proliferation in many, but not all, cell lines (18). In tumor cells, EGFR activation was also EGF-independent. For example, EGFR was activated by mutations $(21,22)$ or by EGF-related peptides that shared a common structural motif of triple intramolecular cysteine bonds (18). Recently, some of the activating mutations have been found to be related to an increased sensitivity to EGFR tyrosine kinase inhibitors in non-small lung cancer $(23,24)$. For prostate cancer, EGFR has been found to be over-expressed in human prostate cancer and may play a role in the progression to more malignant phenotypes (25-28).

In relation to radiation sensitivity, EGFR activation appears to increase the radiation resistance of cancer cells. For example, the activating mutation in EGFR has been linked to the radioresistance of malignant gliomas $(29,30)$. The EGFR overexpression has also been linked to the radioresistance of head and neck epidermoid cancer and the inhibition of EGFR improves the radiosensitivity of the cancer $(13,31)$. Preliminary data have suggested radiation sensitization effects of Iressa, an EGFR inhibitor, in prostate cancer cell lines (32). It has also been suggested that an adenovirus vector-mediated enhancement of the EGFR expression increased the radiation sensitizing effects of anti-EGFR treatments in prostate cancer cells (33). However, much more research is needed to clearly define the potential of using EGFR inhibition in radiation sensitization of prostate cancer cells, especially in prostate cancer cells without a genetically-enhanced EGFR expression. Specifically, we characterized the radiation sensitization effects of C225 (Cetuximab, Erbitux ${ }^{\mathrm{TM}}$ ) in this study. C225 is a $152 \mathrm{kDa}$ chimeric human/murine monoclonal anti-EGFR antibody that specifically binds to the extracellular domain of EGFR. C225 competitively inhibits EGFR and causes tumor regression (20). The toxicity profile of $\mathrm{C} 225$ has been reported and appears to be relatively acceptable with mostly skin toxicities $(34,35)$. This may prove to be a relative advantage over other strategies, such as dose escalation and androgen suppression, in improving prostate cancer radiotherapy outcome.

We found that C225 inhibits cell proliferation of DU145 cells (Figs. 1a, 2a and 3a). This is consistent with other reports (32,36-39). We also found that EGF treatments inhibited the DU145 prostate cell line in vitro (Figs. 1b, 2b and $3 b)$. It has been reported that EGF inhibited cell proliferation in non-prostate cell lines (40). For example, EGF was found to stimulate cell growth of the A431 human epithelial tumor cells at sub-nanomolar concentrations (41), but it was antiproliferative at nanomolar concentrations $(40,42)$. These apparently paradoxical effects of EGF are related to the presence of high and low affinity binding sites of EGF in EGFR (43-45). For prostate cancer cells, at low concentrations (10 ng/ml, or $\sim 2 \mathrm{nM}$ ), EGF was found to have $\sim 10 \%$ proliferative effects on the DU145 cells, but not on the LNCaP or PC3 cells (46). At $5 \mathrm{ng} / \mathrm{ml}$, EGF has been suggested to upregulate DNA repair genes in prostate cancer cells after irradiation and has been suggested to enhance radiation resistance (47). At the higher concentrations that we tested, EGF inhibited the growth of DU145 cells. Taken together, there appeared to be low and high affinity EGF binding sites in the EGFR of DU145 cells. Furthermore, an autocrine/ paracrine stimulation by EGF-like transforming growth factor $\alpha($ TGF- $\alpha)$ (48) in androgen-independent prostate cancer cells has been suggested. The inhibitory patterns that we observed herein were consistent with an interruption of a significant stimulatory autocrine loop in the two DU145 cells. In addition, we found that the inhibition of EGFR pathways augmented the radiation treatment effect on DU145 cells (Figs. 1-3).

We sought to quantify the effect of $\mathrm{C} 225$ on the radiationinduced growth delay of DU145 tumors. The anti-tumor effects of C225 on the DU145 xenograft was analyzed using a two-level hierarchical model, with the natural logarithm of the tumor volume as the dependent variable (16). Thus, the estimated parameters can be interpreted as a daily growth rate. We found that a single dose of $1 \mathrm{mg} / \mathrm{kg}$ of $\mathrm{C} 225$ has about twice the inhibitory effect of $1 \mathrm{~Gy}$ on the growth rate of DU145 xenograft (Fig. 4). Furthermore, the addition of C225 further enhances the antitumor efficacy of radiation (Fig. 4). A typical course of prostate cancer radiotherapy is 75.6 Gy over 42 fractions, thus additional radiation augmentation may be possible when the $\mathrm{C} 225$ is given in repeated doses $(13,31)$. 
We investigated the mechanisms of the radiation sensitization effects of EGF and C225. We found that a significant aspect of the inhibitory effects of EGFR inhibition was cytostatic (Fig. 3). We found that anti-EGFR treatment was associated with a trend of an increased accumulation (albeit statistically not significant) of G1 cells and a decrease in S phase cells in DU145 cells (Fig. 5a). This is consistent with the finding that $\mathrm{C} 225$ induced $\mathrm{G} 1$ arrest and up-regulated the cell cycling inhibitor $\mathrm{p} 27^{\mathrm{KIP} 1}$ in DU145 prostate cancer cells by other investigators (49). Herein, we found that the EGFR inhibition also caused cell cycle delay when the DU145 cells were irradiated (Fig. 5b). The cell cycle analysis also suggested an increase in the sub-G1 fraction (Fig. 5a and b) associated with EGFR inhibition in the DU145 cells. We investigated the relative importance of apoptosis as a mode of cell death in these cells. Our data suggested that there was a mild increase in the Annexin-V:FITC binding (Fig. 6). Thus necrotic cell death is likely to be the dominant cellular response to EGFR inhibition and irradiation, although there is some component of apoptosis involved. Our data are in line with other reports. For example, aromatic quinozoline molecules ZD1839 and PD153035 and specific tyrosine kinase inhibitors (36), have been found to have the mainly cytostatic effects on the LNCaP, DU145 and PC3 prostate cancer cells via G1 arrest with some mild apoptotic effects (32,37-39).

Taken together, our data suggest that the EGFR network may play an important role in prostate cancer survival. C225 increased the treatment effects of radiation in vitro and in vivo. We suggest that the anti-EGFR C225 antibody may be a promising adjunct for prostate cancer radiotherapy. Our data suggest that there may be some interaction between radiation and C225 treatment. More research is clearly needed to fully elucidate the interaction between the EGFR pathway and radiation effect on prostate cancer cells in order to be able to take full advantage of this rich area and its potential for progress.

\section{Acknowledgements}

This research was partially supported by a UT MD Anderson Cancer Center startup grant and a grant from the Elsa U. Pardee Foundation. This study was partially presented at the AACR 2005 Annual Meeting, Anaheim, CA.

\section{References}

1. Jemal A, Tiwari RC, Murray T, et al: Cancer statistics, 2004. CA Cancer J Clin 54: 8-29, 2004.

2. Oesterling JE, Fuks Z, Lee CT and Scher HI: Cancer of the Prostate. In: Cancer Principles and Practice of Oncology, DeVita VT, Hellman S, Rosenberg SA (eds). Vol 1, LippincottRaven, Philadelphia, pp1322-1385, 1997.

3. D'Amico AV, Whittington R, Malkowicz SB, et al: Biochemical outcome after radical prostatectomy, external beam radiation therapy, or interstitial radiation therapy for clinically localized prostate cancer. JAMA 280: 969-974, 1998.

4. Pollack A, Zagars GK, Starkschall G, et al: Prostate cancer radiation dose response: results of the M. D. Anderson phase III randomized trial. Int J Radiat Oncol Biol Phys 53: 1097-1105, 2002.

5. Zelefsky MJ, Fuks Z, Hunt M, et al: High-dose intensitymodulated radiation therapy for prostate cancer: early toxicity and biochemical outcome in 772 patients. Int J Radiat Oncol Biol Phys 53: 1111-1116, 2002.
6. Bolla M, Collette L, Blank L, et al: Long-term results with immediate androgen suppression and external irradiation in patients with locally advanced prostate cancer (an EORTC study): a phase III randomised trial. Lancet 360: 103-106, 2002.

7. Basaria S, Lieb J, Tang AM, DeWeese T, Carducci M, Eisenberger $\mathrm{M}$ and Dobs AS: Long-term effects of androgen deprivation therapy in prostate cancer patients. Clin Endocrinol 56: 779-786, 2002 .

8. D'Amico AV, Manola J, Loffredo M, Renshaw AA, DellaCroce A and Kantoff PW: 6-month androgen suppression plus radiation therapy vs radiation therapy alone for patients with clinically localized prostate cancer: a randomized controlled trial. JAMA 292: 821-827, 2004

9. Padula GD, Zelefsky MJ, Venkatraman ES, Fuks Z, Lee HJ, Natale L and Leibel SA: Normalization of serum testosterone levels in patients treated with neoadjuvant hormonal therapy and three-dimensional conformal radiotherapy for prostate cancer. Int J Radiat Oncol Biol Phys 52: 439-443, 2002.

10. Baumann M and Krause M: Targeting the epidermal growth factor receptor in radiotherapy: radiobiological mechanisms, preclinical and clinical results. Radiother Oncol 72: 257-266, 2004.

11. Harari PM and Huang SM: Combining EGFR inhibitors with radiation or chemotherapy: will preclinical studies predict clinical results? Int J Radiat Oncol Biol Phys 58: 976-983, 2004.

12. Scudiero DA, Shoemaker RH, Paull KD, et al: Evaluation of a soluble tetrazolium/formazan assay for cell growth and drug sensitivity in culture using human and other tumor cell lines. Cancer Res 48: 4827-4833, 1988.

13. Milas L, Fan Z, Andratschke NH and Ang KK: Epidermal growth factor receptor and tumor response to radiation: in vivo preclinical studies. Int J Radiat Oncol Biol Phys 58: 966-971, 2004.

14. Tomayko MM and Reynolds CP: Determination of subcutaneous tumor size in athymic (nude) mice. Cancer Chemother Pharmacol 24: 148-154, 1989.

15. van Engeland M, Nieland LJ, Ramaekers FC, Schutte B and Reutelingsperger CP: Annexin V-affinity assay: a review on an apoptosis detection system based on phosphatidylserine exposure. Cytometry 31: 1-9, 1998.

16. Verbeke G and Molenberohs G: Linear Mixed Models for Longitudinal Data. Springer-Verlag, New York, NY, 2000.

17. Ullrich A, Coussens L, Hayflick JS, et al: Human epidermal growth factor receptor cDNA sequence and aberrant expression of the amplified gene in A431 epidermoid carcinoma cells. Nature 309: 418-425, 1984

18. Carpenter G and Cohen S: Epidermal growth factor. Annu Rev Biochem 48: 193-216, 1979.

19. Ogiso H, Ishitani R, Nureki O, et al: Crystal structure of the complex of human epidermal growth factor and receptor extracellular domains. Cell 110: 775-787, 2002.

20. Mendelsohn J and Baselga J: Status of epidermal growth factor receptor antagonists in the biology and treatment of cancer. J Clin Oncol 21: 2787-2799, 2003.

21. Frederick L, Wang XY, Eley G and James CD: Diversity and frequency of epidermal growth factor receptor mutations in human glioblastomas. Cancer Res 60: 1383-1387, 2000.

22. Pao W, Miller V, Zakowski M, et al: EGF receptor gene mutations are common in lung cancers from 'never smokers' and are associated with sensitivity of tumors to gefitinib and erlotinib. Proc Natl Acad Sci USA 101: 13306-13311, 2004.

23. Lynch TJ, Bell DW, Sordella R, et al: Activating mutations in the epidermal growth factor receptor underlying responsiveness of non-small-cell lung cancer to gefitinib. N Engl J Med 350: 2129-2139, 2004.

24. Paez JG, Janne PA, Lee JC, et al: EGFR mutations in lung cancer: correlation with clinical response to gefitinib therapy. Science 304: 1497-1500, 2004.

25. Scher HI, Sarkis A, Reuter V, et al: Changing pattern of expression of the epidermal growth factor receptor and transforming growth factor alpha in the progression of prostatic neoplasms. Clin Cancer Res 1: 545-550, 1995.

26. Zellweger T, Ninck C, Bloch M, et al: Expression patterns of potential therapeutic targets in prostate cancer. Int J Cancer 113: 619-628, 2005.

27. Di Lorenzo G, Tortora G, D'Armiento FP, et al: Expression of epidermal growth factor receptor correlates with disease relapse and progression to androgen-independence in human prostate cancer. Clin Cancer Res 8: 3438-3444, 2002. 
28. Torring N, Dagnaes-Hansen F, Sorensen BS, Nexo E and Hynes NE: ErbB1 and prostate cancer: ErbB 1 activity is essential for androgen-induced proliferation and protection from the apoptotic effects of LY294002. Prostate 56: 142-149, 2003.

29. Li B, Yuan M, Kim IA, Chang CM, Bernhard EJ and Shu HK: Mutant epidermal growth factor receptor displays increased signaling through the phosphatidylinositol-3 kinase/AKT pathway and promotes radioresistance in cells of astrocytic origin. Oncogene 23: 4594-4602, 2004.

30. Lammering G, Hewit TH, Holmes M, et al: Inhibition of the type III epidermal growth factor receptor variant mutant receptor by dominant-negative EGFR-CD533 enhances malignant glioma cell radiosensitivity. Clin Cancer Res 10: 6732-6743, 2004

31. Ang KK, Andratschke NH and Milas L: Epidermal growth factor receptor and response of head-and-neck carcinoma to therapy. Int J Radiat Oncol Biol Phys 58: 959-965, 2004.

32. Sgambato A, Faraglia B, Ardito R, et al: Targeted inhibition of the epidermal growth factor receptor-tyrosine kinase by ZD1839 ('Iressa') induces cell-cycle arrest and inhibits proliferation in prostate cancer cells. J Cell Physiol 201: 97-105, 2004.

33. Bonner JA, Buchsbaum DJ, Rogers BE, et al: Adenoviral vector-mediated augmentation of epidermal growth factor receptor $(\mathrm{EGFr})$ enhances the radiosensitization properties of anti-EGFr treatment in prostate cancer cells. Int J Radiat Oncol Biol Phys 58: 950-958, 2004.

34. Busam KJ, Capodieci P, Motzer R, Kiehn T, Phelan D and Halpern AC: Cutaneous side-effects in cancer patients treated with the antiepidermal growth factor receptor antibody $\mathrm{C} 225 . \mathrm{Br}$ J Dermatol 144: 1169-1176, 2001.

35. Bonner JA, Harari PM, Giralt J, et al: Radiotherapy plus cetuximab for squamous-cell carcinoma of the head and neck. N Engl J Med 354: 567-578, 2006.

36. Rewcastle GW, Palmer BD, Thompson AM, et al: Tyrosine kinase inhibitors. 10. Isomeric 4-[(3-bromophenyl)amino]pyrido[d]-pyrimidines are potent ATP binding site inhibitors of the tyrosine kinase function of the epidermal growth factor receptor. J Med Chem 39: 1823-1835, 1996.

37. Mimeault M, Pommery N and Henichart JP: Synergistic antiproliferative and apoptotic effects induced by epidermal growth factor receptor and protein kinase a inhibitors in human prostatic cancer cell lines. Int J Cancer 106: 116-124, 2003.

38. Barker AJ, Gibson KH, Grundy W, et al: Studies leading to the identification of ZD1839 (IRESSA): an orally active, selective epidermal growth factor receptor tyrosine kinase inhibitor targeted to the treatment of cancer. Bioorg Med Chem Lett 11: 1911-1914, 2001.
39. Wakeling AE, Guy SP, Woodburn JR, Ashton SE, Curry BJ, Barker AJ and Gibson KH: ZD1839 (Iressa): an orally active inhibitor of epidermal growth factor signaling with potential for cancer therapy. Cancer Res 62: 5749-5754, 2002.

40. Barnes DW: Epidermal growth factor inhibits growth of A431 human epidermoid carcinoma in serum-free cell culture. J Cell Biol 93: 1-4, 1982.

41. Kawamoto T, Sato JD, Le A, Polikoff J, Sato GH an Mendelsohn J: Growth stimulation of A431 cells by epidermal growth factor: identification of high-affinity receptors for epidermal growth factor by an anti-receptor monoclonal antibody. Proc Natl Acad Sci USA 80: 1337-1341, 1983.

42. Gill GN and Lazar CS: Increased phosphotyrosine content and inhibition of proliferation in EGF-treated A431 cells. Nature 293: 305-307, 1981

43. King AC and Cuatrecasas P: Resolution of high and low affinity epidermal growth factor receptors. Inhibition of high affinity component by low temperature, cycloheximide, and phorbol esters. J Biol Chem 257: 3053-3060, 1982.

44. Zhang L, Gjoerup O and Roberts TM: The serine/threonine kinase cyclin G-associated kinase regulates epidermal growth factor receptor signaling. Proc Natl Acad Sci USA 101: 10296-10301, 2004

45. Klein P, Mattoon D, Lemmon MA and Schlessinger J: A structure-based model for ligand binding and dimerization of EGF receptors. Proc Natl Acad Sci USA 101: 929-934, 2004.

46. Sgambato A, Camerini A, Faraglia B, et al: Targeted inhibition of the epidermal growth factor receptor-tyrosine kinase by ZD1839 ('Iressa') induces cell-cycle arrest and inhibits proliferation in prostate cancer cells. Cell Physiol 201: 97-105, 2004.

47. Yacoub A, McKinstry R, Hinman D, Chung T, Dent P and Hagan MP: Epidermal growth factor and ionizing radiation upregulate the DNA repair genes XRCC1 and ERCC1 in DU145 and LNCaP prostate carcinoma through MAPK signaling. Radiat Res 159: 439-452, 2003.

48. Hofer DR, Sherwood ER, Bromberg WD, Mendelsohn J, Lee C and Kozlowski JM: Autonomous growth of androgenindependent human prostatic carcinoma cells: role of transforming growth factor alpha. Cancer Res 51: 2780-2785, 1991.

49. Peng D, Fan Z, Lu Y, DeBlasio T, Scher H and Mendelsohn J: Anti-epidermal growth factor receptor monoclonal antibody 225 up-regulates p27KIP1 and induces G1 arrest in prostatic cancer cell line DU145. Cancer Res 56: 3666-3669, 1996. 